\title{
Complete Adipose Replacement of Bilateral Medial Gastrocnemius Muscle - A Cadaveric Case Report
}

\author{
Charles Nichols ${ }^{1}$, Elizabeth Liu², Howe Liü \\ ${ }^{1}$ Department of Physical Therapy, University of North Texas Health Science Center, ${ }^{2}$ School of Dentistry, University of Texas Health Science Center at San \\ Antonio. San Antonio, TX, USA, ${ }^{3}$ Department of Physical Therapy, University of North Texas Health Science Center. Fort Worth, TX. USA.
}

\section{Abstract}

Sarcopenia and infiltration of intermuscular adipose tissue are often seen in older adults due to aging process, but a muscle is completely replaced by adipose tissue is rarely reported. In this cadaveric case, we describe an observation of bilateral symmetric adipose replacement of the medial gastrocnemius muscles (GM) on both left and right leg in an 82-year old Caucasian female, whose cause of death was advanced dementia. The white adipose tissue replaced the entire medial GM muscle belly with pennate-like arrangement, indicating adipose tissue infiltration very likely into the original muscle cells. Where and how these adipose tissues come from are discussed.

Keywords: Intermuscular adipose tissue, Fatty infiltration, Cadaver, Lower extremity.

Corresponding Author: Dr. Howe Liu, Department of Physical Therapy, University of North Texas Health Science Center. Fort Worth, TX. USA. 76107.

Email: howe.liu@unthsc.edu

Received: $12 / 5 / 2020$

Revised: $22 / 6 / 2020$

Accepted: $24 / 6 / 2020$

\section{Introduction}

Frailty is a geriatric syndrome that makes susceptible older adults to unfavorable events such as muscle deterioration due to sarcopenia and mobility dysfunction. ${ }^{[1,2]}$ Sarcopenia is an aging process of body composition changes showing decreased skeletal muscle mass and increased body fat. ${ }^{[3,4]}$ Skeletal muscle is fundamentally important for force generation and movement control. The muscles could be replaced by adipose tissues to become dysfunctional under certain physiological and/or pathological conditions for example the older age and/or severe muscle injury. ${ }^{[5]}$

Injury or disease to a muscle might cause loss of myofibers and consequently increase of adipocytes in the muscle. ${ }^{[6]}$ It was reported that in a patient with myotonic dystrophy, a muscle could be replaced entirely by adipose tissue. ${ }^{[7]}$ Such an adipose infiltration in skeletal muscles could be seen in other medical conditions and is highly associated with age..$^{[5,8]}$ The older age along with other predisposing factors like injury could cause redistribution of adipose tissue deposits, regardless of stable or decreasing overall adipose tissue, with adipose storage sites changing from a subcutaneous location to other places like skeletal muscles ${ }^{[8]}$ Infiltration of adipose tissue into skeletal muscles is often defined as Intermuscular adipose tissue (IMAT), which is often seen inert lipid storage deposit underneath the fascia of muscle. ${ }^{[8-10]}$ The IMAT can be located between muscles or within a muscle as intermuscular or intramuscular adipose tissue. ${ }^{[8,10]}$ Physiologically, the increased body fat in an elderly person usually deposits in visceral adipose tissue, subcutaneous adipose tissue, and intermuscular adipose tissue (IMAT) ${ }^{[3]} \mathrm{In}$ medical school anatomy labs, it is easy during dissection to identify these adipose tissues in subcutaneous and visceral areas, but IMAT within a muscle, particularly within an entire muscle, is rarely encountered. Thus, In this case we describe a morphological appearance of bilateral medial gastrocnemius muscles (GMs) replaced completely by fatty tissue that has not been previously reported.

\section{Case Report}

The donor was an 82-year old Caucasian female whose cause of death was advanced dementia. During the routine cadaveric dissection of the posterior legs in medical school anatomy lab at the authors' institution, an anomalous variation was identified in this female cadaver. After removing the skin and subcutaneous tissue to show the posterior compartment on both left and right lower legs, the GMs on both sides were exposed. The whole muscle belly of the lateral head showed like a normal-looking muscle; while the whole muscle belly of the medial head seemed to be replaced completely by adipose tissue [Figure 1]. These adipose medial GMs on both sides start from its origin immediately distal to the adductor tubercle covered by 
semimembranosus and semitendinosus muscles, and ends at the musculotendinous junction where the medial head converges to form the calcaneal tendon [Figure 1].

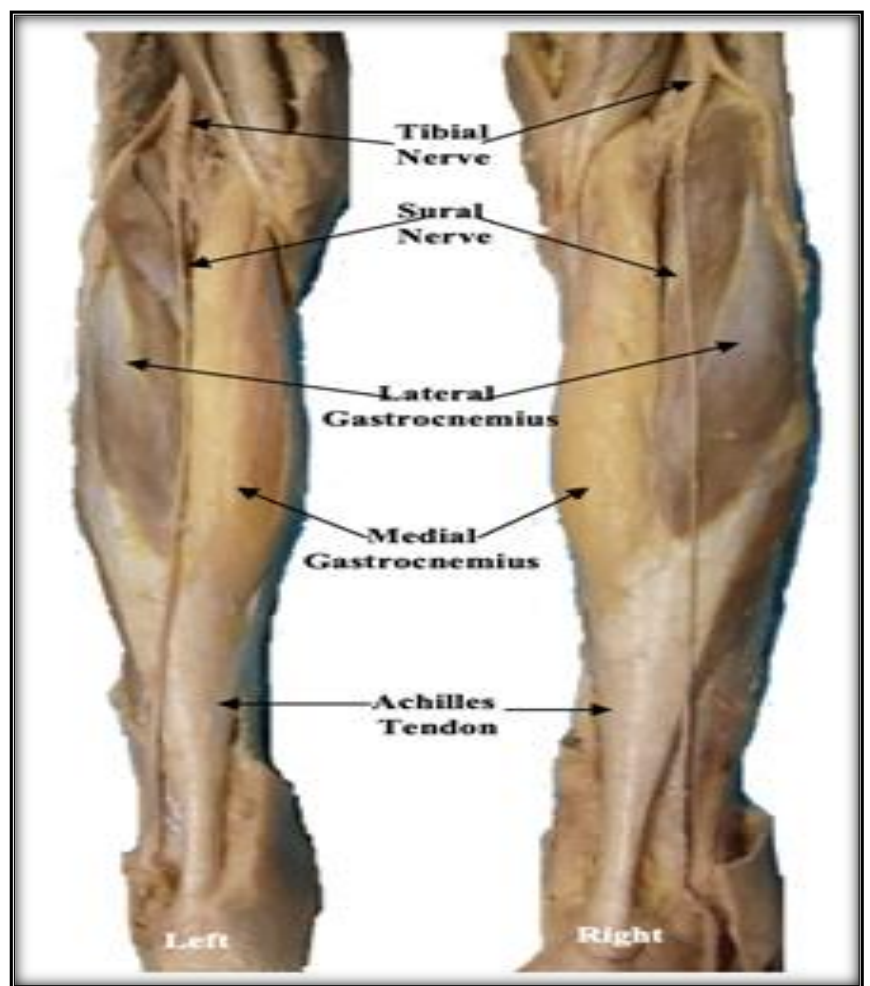

Figure 1: Posterior view of both legs shows symmetric adipose tissue replacement of entire medial gastrocnemius muscles on both left and right legs.

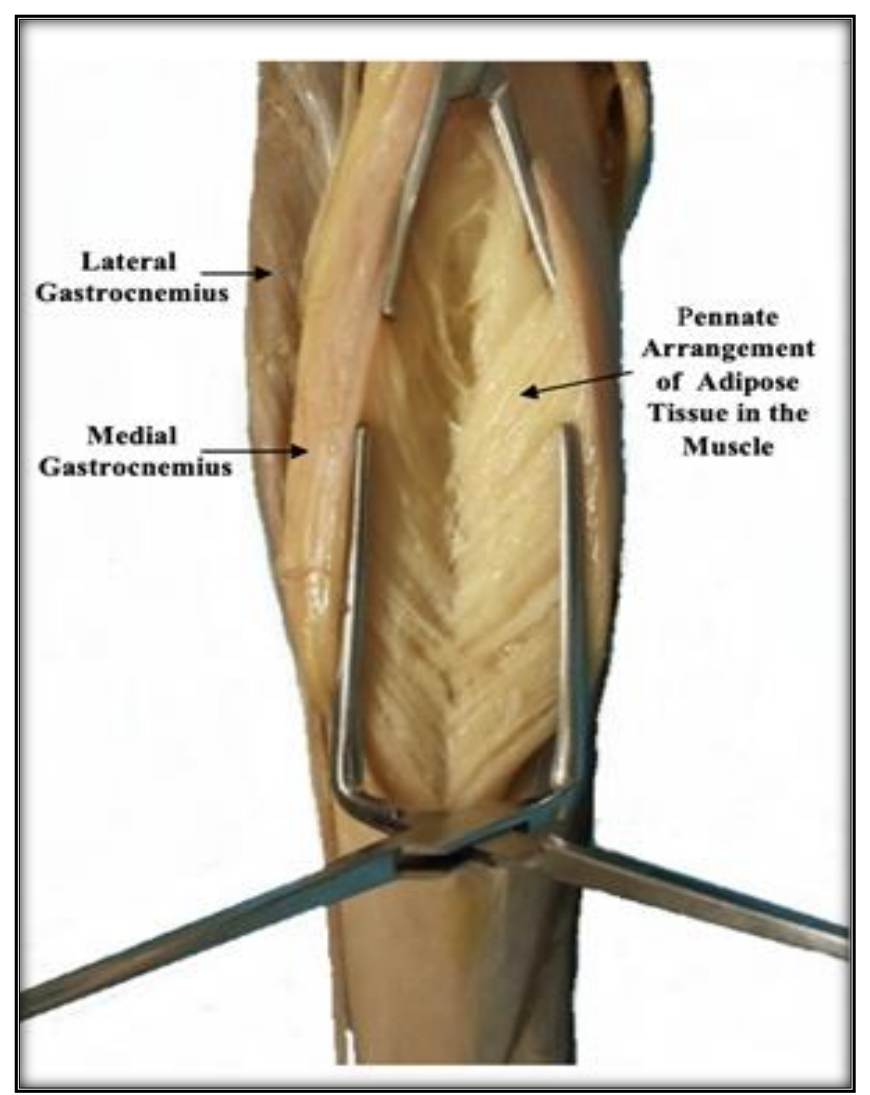

Figure 2: Posterior view of left gastrocnemius muscle: the medial gastrocnemius is cut open vertically and shows the pennate arrangement of adipose tissue in the muscle.
It is clear to see the demarcation lines in the muscular lateral head and adipose medial head, as well as between the adipose muscle belly and the tendinous Achilles tendon on the medial GM [Figure 2].

After a vertical incision was made along the medial GM belly on both left and right sides, the belly was then opened up with a surgical retractor. It showed that the supposed pennate arrangement of the GM was fully replaced by white adipose tissue which was still in bipennate array [Figure 2]. Further, dissection in the popliteal fossa area also revealed that soleus muscles was normal, and the tibial nerve and popliteal vessels had 1-2 muscular branches to the medial and lateral GM on both sides. The diameters of these branches to the medial and lateral heads did not differ as visualized with the naked eye. Additionally, no mass, cyst, enlarged lymph nodes, varicose vessels, swollen tissue, or bone abnormality was identified or palpated in the posterior leg from the knee to the ankle. It also should be noted that this cadaver was not over-weight in appearance prior to dissection.

\section{Discussion}

To our knowledge, this case is second time showing a bilateral symmetric muscles replaced entirely by adipose tissue. In 2011, Ina et al, ${ }^{[11]}$ observed bilateral sartorius muscles replaced by white adipose tissue and the whole muscle appeared as fat on an 86-year-old Japanese male cadaver during regular dissection for medical students. In this case, ${ }^{[11]}$ the male donor was bedridden during his late life and cause of death was renal failure. The author thought that adipose replacement or degeneration of the sartorius muscles appeared to result from possible medical history and bedridden status that could lead to muscle atrophy and damage, consequently the sarcopenia. ${ }^{[11]}$ In our present case, the cause of death was advanced dementia, which could cause a bedridden status and inactivity, which accordingly could lead to increased IMAT in the GM.$^{[1,10]}$

Embryologically, skeletal muscles, including the GM, derive from the paraxial mesoderm. ${ }^{[12]}$ As a part of mesoderm of an embryo, the mesenchyme can be found throughout the whole life span and is able to develop into connective tissues like muscles and adipose tissues, cartilage, and bones. ${ }^{[13]}$ Adipose tissue comprises adipose stem cells, adipocytes, and various other cells; and can deposit in various places of human body including skeletal muscles. ${ }^{[14]}$ In adult humans, these adipose progenitor cells are able to proliferate and differentiate into adipocytes continuously at substantial rates, ${ }^{[13,15]}$ when they are cued or induced by environmental, physiological, and pathological factors like aging processes and muscle injury. ${ }^{[14,15]}$ In the present case, the donor's medical history was not available, but her age (82 years old) and medical diagnosis advanced dementia (possibly causing a bedridden status and inactivity) might be the inducing factors of adipogenic process in muscles. So, we are in agreement with the previous case speculating that the origin of adipocytes in the muscles replaced by fat might be from mesenchymal progenitors in muscle tissue. ${ }^{[1]}$

Studies have demonstrated that the lower extremity, particularly the thigh area, is a common for the IMAT. ${ }^{\left[{ }^{[-10]}\right.}$ It matched well with the cadaveric case report of adipose tissue deposit as the IMAT in the whole bilateral sartorius muscles 
at the anteromedial thigh of an 86-year old male. ${ }^{[11]}$ In comparison, our cadaveric case appears to have a similar pattern of adipose deposition - entire fatty replacement of bilateral medial gastrocnemius muscles. Literature has exerted that adipocytes exist in skeletal muscles and the number of these cells can increase if the muscle is injured. ${ }^{[6,12]}$ However, it is still unknown which and how a specific muscle or muscles would respond more to the injury. Sartorius is a slender strap muscle with parallel muscle fiber arrangement, while the gastrocnemius is a big and wide pennate muscle with feather-like fiber arrangement, indicating adipose tissue infiltration very likely into the original muscle cells. With adipose replacement of the muscles on both left and right lower extremity, although it is puzzling to us, we believe that the triggering point for this symmetric fatty appearance might occur at a higher level, probably in the central nervous system.

\section{Conclusion}

Symmetric appearance of complete adipose tissue infiltration into bilateral medial gastrocnemius muscles was observed in this case report. Pennate-like arrangement of adipose tissue in these muscles may indicate intracellular infiltration into the original muscle cells. Why and how this was triggered to happen in this older cadaveric donor, but long-term bedridden and pre-existed mesenchymal progenitors in muscle tissue might be the triggering factors that work interactively to cause the adipose replacement of these muscles. Such replacement seemed to occur more likely in the weight-bearing lower extremity.

\section{References}

1. Marcus RL, Addison O, LaStayo PC. Intramuscular adipose tissue attenuates gains in muscle quality in older adults at high risk for falling. A brief report. J Nutr Health Aging. 2013;17(3):215-218. doi:10.1007/s12603-012-0377-5

2. Bentov I, Kaplan SJ, Pham TN, Reed MJ. Frailty assessment: from clinical to radiological tools. Br J Anaesth. 2019;123(1):37-50. doi:10.1016/j.bja.2019.03.034

3. Song MY, Ruts E, Kim J, Janumala I, Heymsfield S, Gallagher D.
Sarcopenia and increased adipose tissue infiltration of muscle in elderly African American women. Am J Clin Nutr. 2004;79(5):874-880. doi:10.1093/ajcn/79.5.874

4. Hanna JS. Sarcopenia and critical illness: a deadly combination in the elderly. JPEN J Parenter Enteral Nutr. 2015;39(3):273-281. doi: $10.1177 / 0148607114567710$

5. Uezumi A, Ikemoto-Uezumi M, Tsuchida K. Roles of nonmyogenic mesenchymal progenitors in pathogenesis and regeneration of skeletal muscle. Front Physiol. 2014;5:68. Published 2014 Feb 24. doi:10.3389/fphys.2014.00068

6. Carpenter S, Karpati G. Cells and structures other than skeletal muscle fibers. In: Carpenter S,Karpati G. ed. Pathology of Skeletal Muscle, 2nd Ed. New York, NY: Oxford; 2001:314-369.

7. Banker BQ, Engel AG. Basic reactions of muscle. In: Engel AG, Franzini-Armstrong C. ed. Myology, 3rd Ed. New York, NY: McGraw-Hill:2004:691-747.

8. Addison O, Marcus RL, Lastayo PC, Ryan AS. Intermuscular fat: a review of the consequences and causes. Int $\mathrm{J}$ Endocrinol. 2014;2014:309570. doi:10.1155/2014/309570

9. Zoico E, Rossi A, Di Francesco V, et al. Adipose tissue infiltration in skeletal muscle of healthy elderly men: relationships with body composition, insulin resistance, and inflammation at the systemic and tissue level. J Gerontol A Biol Sci Med Sci. 2010;65(3):295299. doi:10.1093/gerona/glp155

10. Addison O, Drummond MJ, LaStayo PC, et al. Intramuscular fat and inflammation differ in older adults: the impact of frailty and inactivity. J Nutr Health Aging. 2014;18(5):532-538. doi:10.1007/s12603-014-0019-1

11. Ina K, Kitamura H, Masaki $T$, Tatsukawa S, Yoshimatsu H, Fujikura Y. Human skeletal muscles replaced to a high degree by white adipose tissue. Okajimas Folia Anat Jpn. 2011;87(4):165170. doi:10.2535/ofaj.87.165

12. Warmbrunn MV, de Bakker BS, Hagoort J, Alefs-de Bakker PB, Oostra RJ. Hitherto unknown detailed muscle anatomy in an 8week-old embryo. J Anat. 2018;233(2):243-254. doi:10.1111/joa.12819

13. Spalding KL, Arner E, Westermark PO, et al. Dynamics of fat cell turnover in humans. Nature. 2008;453(7196):783-787. doi:10.1038/nature06902

14. Berry DC, Stenesen D, Zeve D, Graff JM. The developmental origins of adipose tissue. Development. 2013;140(19):3939-3949. doi: $10.1242 /$ dev.080549

15. Uezumi A, Ito T, Morikawa D, et al. Fibrosis and adipogenesis originate from a common mesenchymal progenitor in skeletal

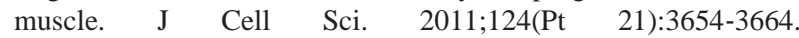
doi:10.1242/jcs.086629.

Copyright: () the author(s), 2020. It is an open-access article distributed under the terms of the Creative Commons Attribution License (CC BY 4.0), which permits authors to retain ownership of the copyright for their content, and allow anyone to download, reuse, reprint, modify, distribute and/or copy the content as long as the original authors and source are cited.

which permits unrestricted non-commercial use, distribution, and reproduction in any medium, provided the original work is properly cited.

How to cite this article: Nichols C, Liu E, Liu H. Complete Adipose Replacement of Bilateral Medial Gastrocnemius Muscle - A Cadaveric Case Report. Acad. Anat. Int. 2020;6(1):62-64.

DOI: dx.doi.org/10.21276/aanat.2020.6.1.14

Source of Support: Nil, Conflict of Interest: None declared. 